\title{
OEDEMATOUS SKIN DISEASE, A COMPARISON OF CHANGEABLE CLINICAL NATURE IN CATTLE AND BUFFALO
}

\author{
Atef F. Oreiby ${ }^{1}$, Sahar A. Abo El-Wafa', Yamen M. Hegazy ${ }^{1}$ \\ and Magdy H. Al-Gaabary ${ }^{1}$ \\ ${ }^{1}$ Animal Medicine Department, Faculty of Veterinary Medicine, \\ Kafrelsheikh University, Egypt \\ ${ }^{2}$ Animal Medicine Department, Faculty of Veterinary Medicine, \\ Assiut University, Egypt
}

\begin{abstract}
Oedematous skin disease (OSD) is a pyogenic bacterial disease affects buffalo and cattle. OSD is endemic in Egypt with temporal cyclic nature. An outbreak of OSD was reported in Zefta region of Gharbia governorate during spring and summer 2014. This study was performed to investigate some epidemiological, clinical and therapeutic trials associated with OSD in this outbreak. The prevalence of OSD in this outbreak was estimated at 7.1\% (7.3\% and $6.3 \%$ among buffalo and cattle respectively). Prevalence of OSD was higher in summer months than spring associated with increase of fly activity and population. Clinically, there were different forms of the disease in both buffalo and cattle; edematous, fistulous- edematous, ulcerative and nodular forms. All forms were found associated with involvement of regional lymphatics. Haemoglobinuria and pneumonia were the reported complications that terminated by death in two buffaloes. In this study, increased severity of OSD in cattle was observed indicating increased adaptability of the micro-organism to cattle. It is concluded that, flies is playing the main role in transmission of C. pseudotuberculosis infection. Also, OSD has a real temporal cyclic nature and increased adaptability to cattle.
\end{abstract}




\section{INTRODUCTION}

Oedematous Skin Disease is a subacute bacterial disease which usually affects buffalo and cattle (Abou-Zaid, 2001). OSD causes financial losses to the Egyptian farmer due to reduction of productivity, decreased work efficiency, expensive medications which accompany the long course of the disease in addition to surgical intervention (Selim, 2001 and Sayed et al., 2007). The disease is caused by a gram positive pleomorphic facultative intracellular bacterium, C. pseudotuberculosis, (Khater et al., 1984: Barakat et al., 1985 and Abd El Latif, 2011) that invades host body either through skin wounds and abrasions (Arab et al., 1988 and Syame et al., 2008) or by insect bites (Addo, 1983: Hamoda, 1996: Braverman et al., 1999 and Selim, 2001).

The disease expresses itself in different forms (Al-Gaabary and Ammar, 1999: Zaki, 2004 and Al-Gaabary et al. 2005): oedematous, ulcerative, nodular and mixed forms. Lesions mostly appear in limbs but sometimes other regions are involved associated with swelling of regional draining lymph node (Hamoda, 1996 and Abou-Zaid, 2001). OSD is more prevalent and more severe in buffaloes than cows. The oedematous form was reported mainly in buffaloes while the ulcerative form was the predominant form in cattle (Al-Gaabary et al.,2005).

In Egypt, OSD has a temporal pattern where most cases usually appear in summer (Mostafa, 1984). Additionlly, the prevalence of the disease is usually reported to be significantly higher in buffaloes than cattle (Al-Gaabary et al., 2005). 
During March to June, 2014, there was an outbreak of OSD among cattle and buffaloes in Zefta region of Gharbia governorate with some new features in clinical and epidemiological aspects. This study aimed to determine the pattern of occurrence associated with OSD in this outbreak at Gharbia governorate, 2014.

\section{MATERIALS AND METHODS}

\section{Animals and clinical examination:}

A total of 480 animals (112 cattle and 368 buffalo) of different ages were subjected to clinical examination according to (Rosenberger et al. 1979) during the period from March to June, 2014 at Zefta region.

\section{Bacteriological examination:}

\section{Samples:}

Pus samples were collected aseptically from clinical cases to confirm diagnosis. It was collected by aspiration from closed lesions or through aseptic swabbing from opened lesions and was sent on ice to the laboratory at which microbiological investigations were performed.

\section{Bacterial isolation and identification:}

Samples were cultured on tryptose soya agar plates then incubated aerobically at $37^{\circ} \mathrm{C}$ for $48-72$ hours for the initial isolation according to (Bailey and Scott, 1990). After 48-72 hours incubation, the resultant colonies were examined for consistency, color in addition to their ability to be pushed across the agar surface (Selim, 2001). Films were prepared from the colonies and stained with Gram's stain then examined microscopically. The ability of the bacterial cells to attain the stain, shape and the arrangement of the bacterial cells were examined. 


\section{Medical treatment:}

All diseased animals were subjected to medicinal and nursing treatment. Long acting oxytetracycline with non steroidal antiinflammatory with complete rest and using of fly repellent was used for all cases during the whole course of the disease. Local dressing with antibiotic (Gramycine) was used for the opened lesions and ulcers. Surgical treatment was applied for the ripened oedematous lesions.

\section{Epidemiological examination:}

The prevalence of OSD was estimated by dividing the total number of diseased animals by the whole number of exposed animals then multiplied by 100 . The course of OSD was estimated as the period between the appearance of the disease to the complete recovery or death. The temporal distribution was studied during different months of the study period by estimating the prevalence of OSD every month.

\section{RESULTS}

\section{Prevalence and clinical examination:}

The prevalence of the disease in this outbreak was estimated at $7.1 \%$ (34 diseased animals out of 480 examined animals). The prevalence in buffaloes was $7.3 \%$ (27 diseased out of 368 examined) and it was $6.3 \%$ among cattle (7 diseased out of 112 examined), Table 1.

Clinically, the general systemic state of the diseased animals was unchanged. Appetite, respiration, rumination, defecation and rumination were normal in most animals that showed clinical signs of OSD except 
for two complicated cases. OSD expressed itself in several forms: oedematous, nodular, ulcerative and fistulous-edematous forms which may be present independently or in association with other forms, figures 1 to 7 . The distribution of different forms among buffaloes and cows is showed in table 1 .

Oedmatous form was more common in buffalo than cattle. Out of 27 diseased buffalo, 12 showed lesion that was characterized by initial inflammatory swelling at the site of affection which may either resolve, if early therapeutic intervention is participated, or later on such swelling increases in size due to progress of the condition and accumulation of pyogenic materials. Such lesions were mostly closed. Fistulousedematous form was recorded in 11 out of 27 diseased buffalo. The lesions were discharging brownish bloody exudate. Oedematous lesions were mostly detected in limbs particularly hind limbs but infrequently located at the chest, ventral abdomen, neck and head with the involvement of local drainage lymph nodes. Cows did not suffer from these two forms.

Ulcerative form was the only form that was reported in cattle. It also was reported only in 5 diseased buffalo. Ulcerative form was characterized by suddenly occuring long lasting ulcers that ooze bloody or creamy pyogenic materials. Ulcers were mostly found on the course of lymphatic vessels particularly in limbs and chest regions. Lymph node of the affected area mostly found swollen. Flies always were found to accumulate around the lesion. 
Atef F. Oreiby et., al.

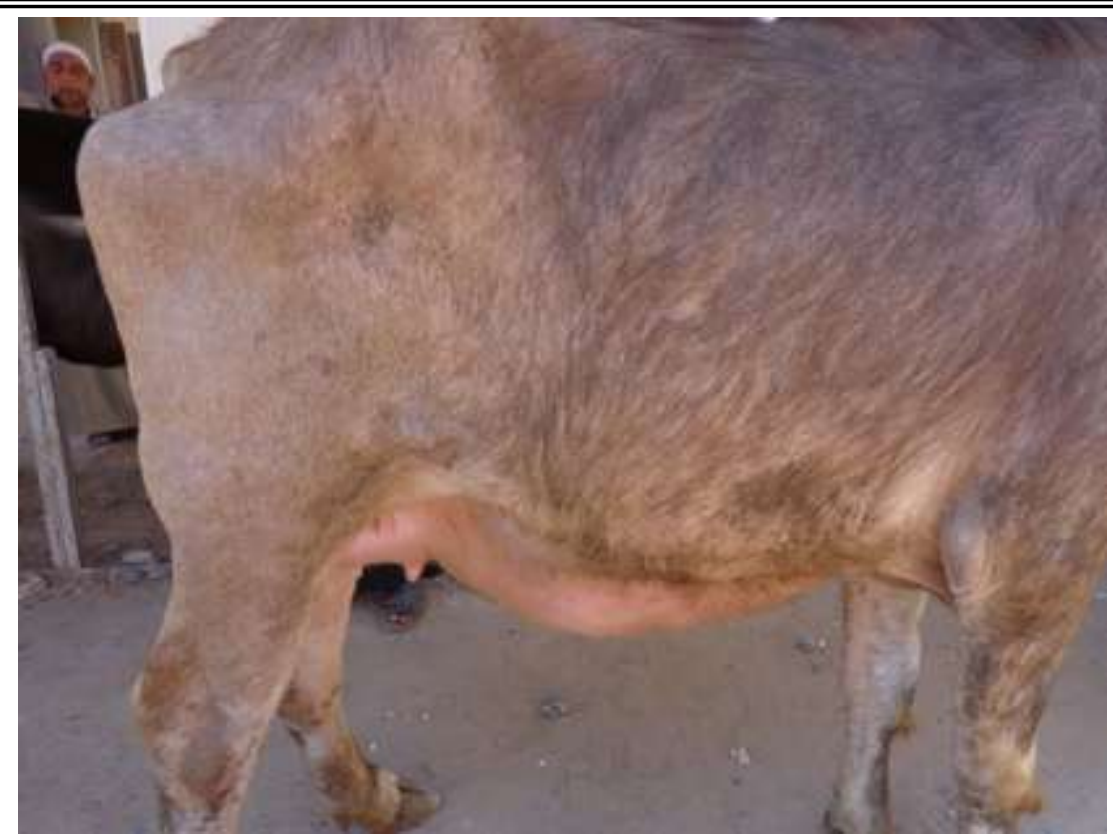

Fig. (1): Buffalo showing edematous form at abdomen region.

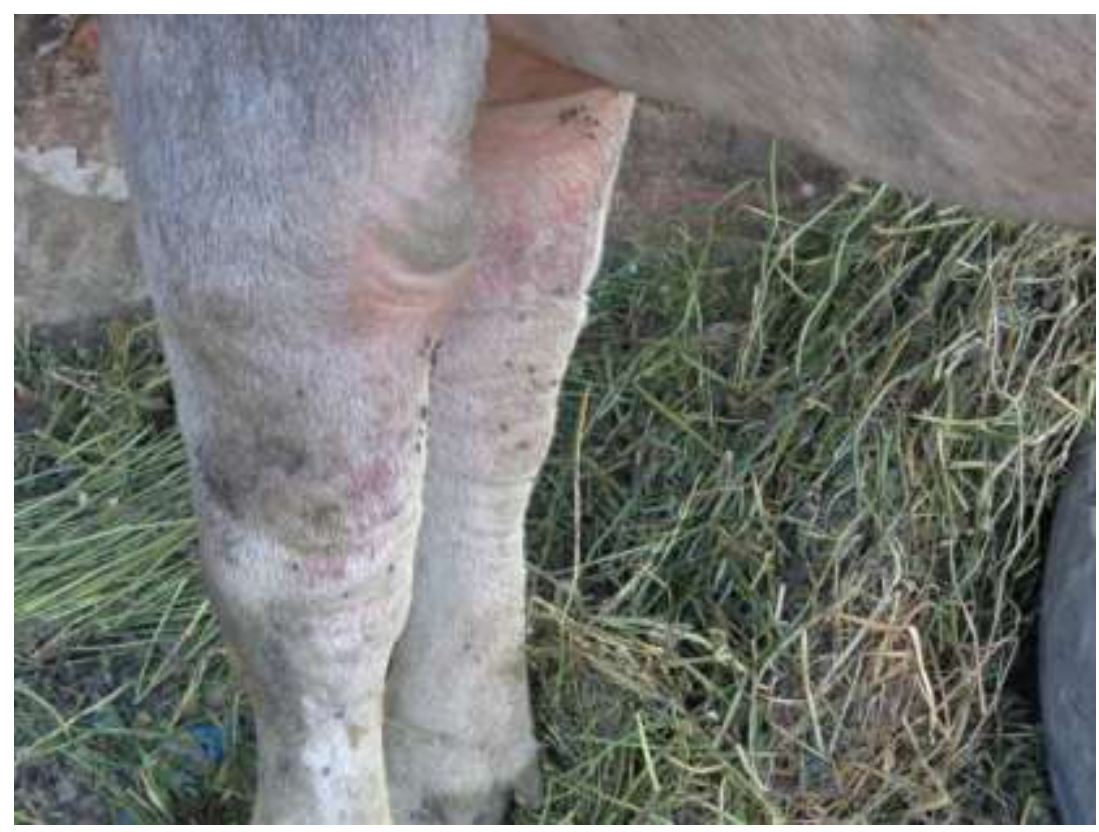

Fig. (2): Buffalo showing bilateral forelimbs swelling

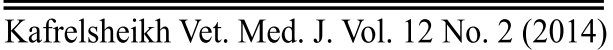




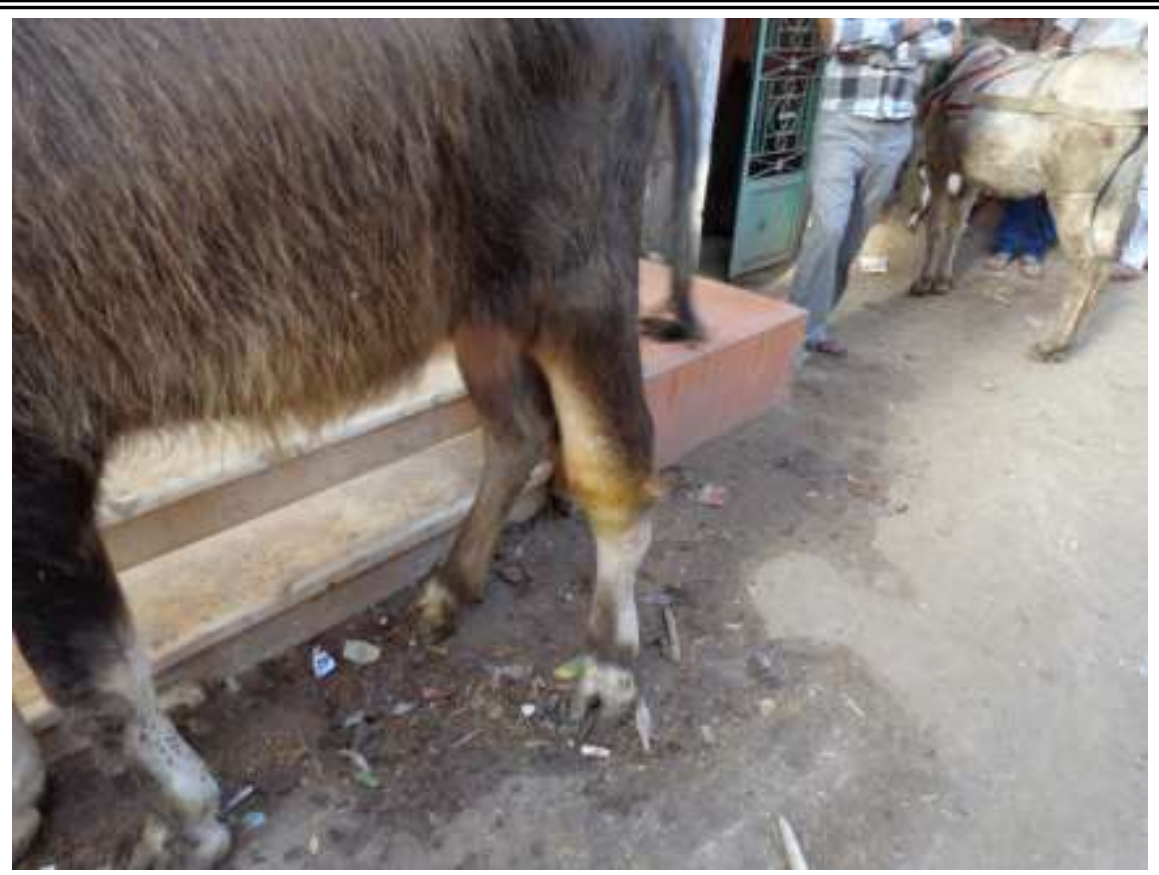

Fig. (3): Buffalo showing unilateral swelling at left hind limb.

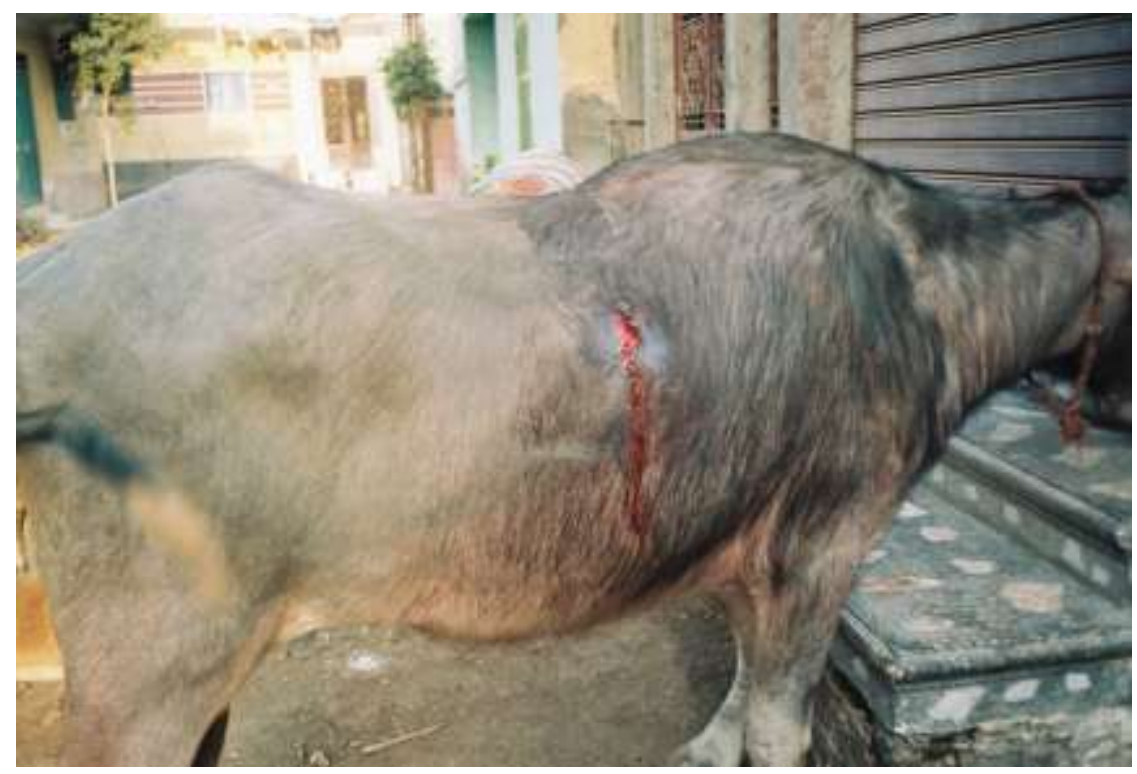

Fig. (4): Buffalo showing ulcerative form at chest region. 
Atef F. Oreiby et., al.

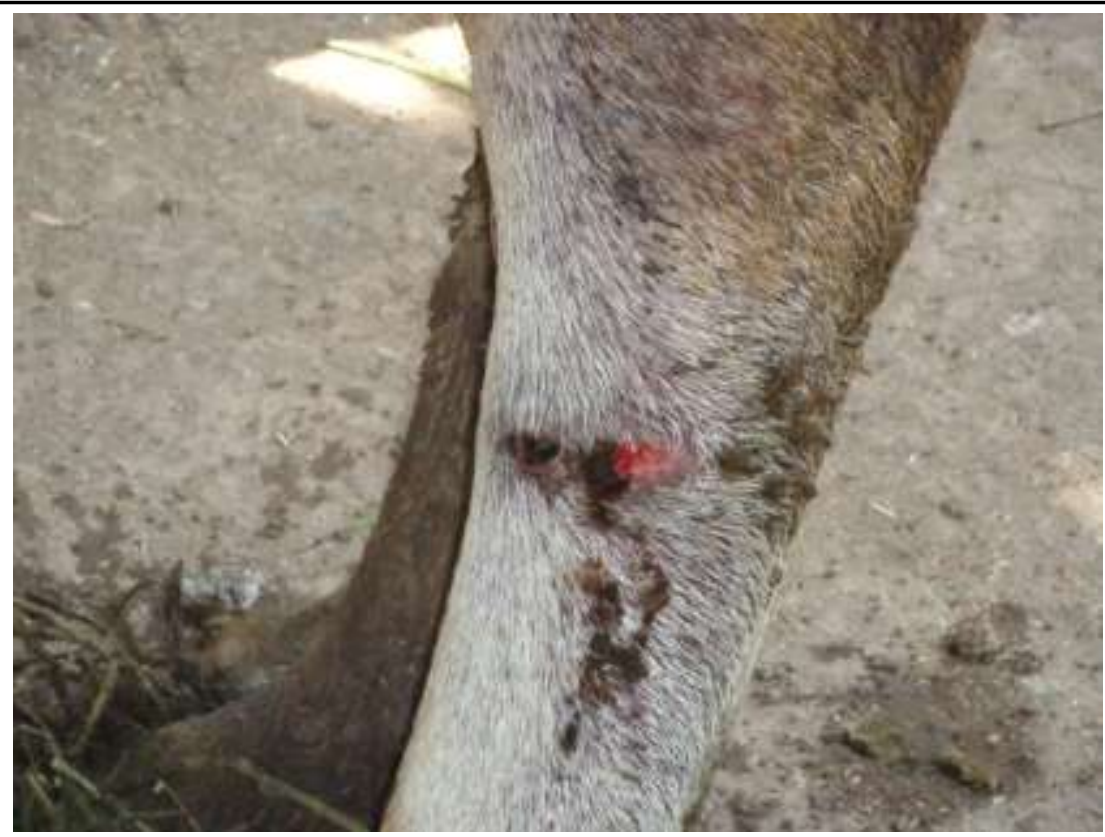

Fig. (5): Buffalo showing ulcerative form at left hind limb.

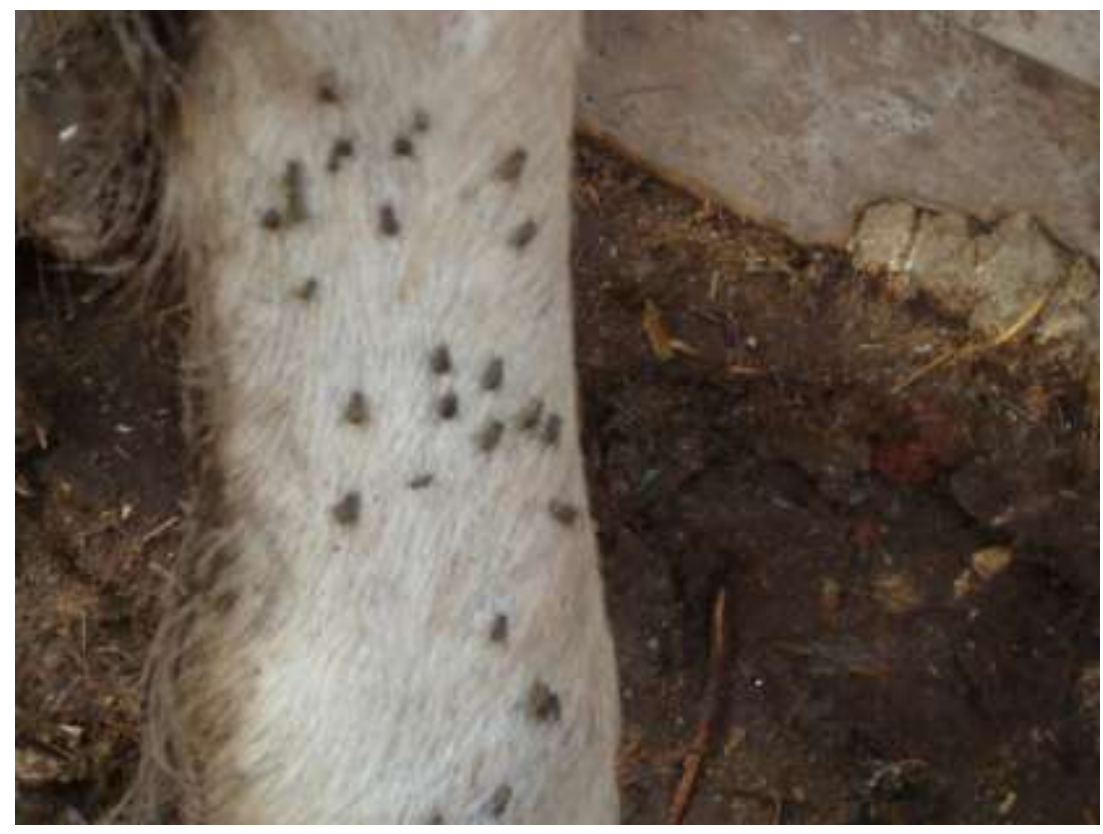

Fig. (6): Accumulation of flies around edematous lesion in a buffalo. 
Oedematous Skin Disease, A Comparison Of ...

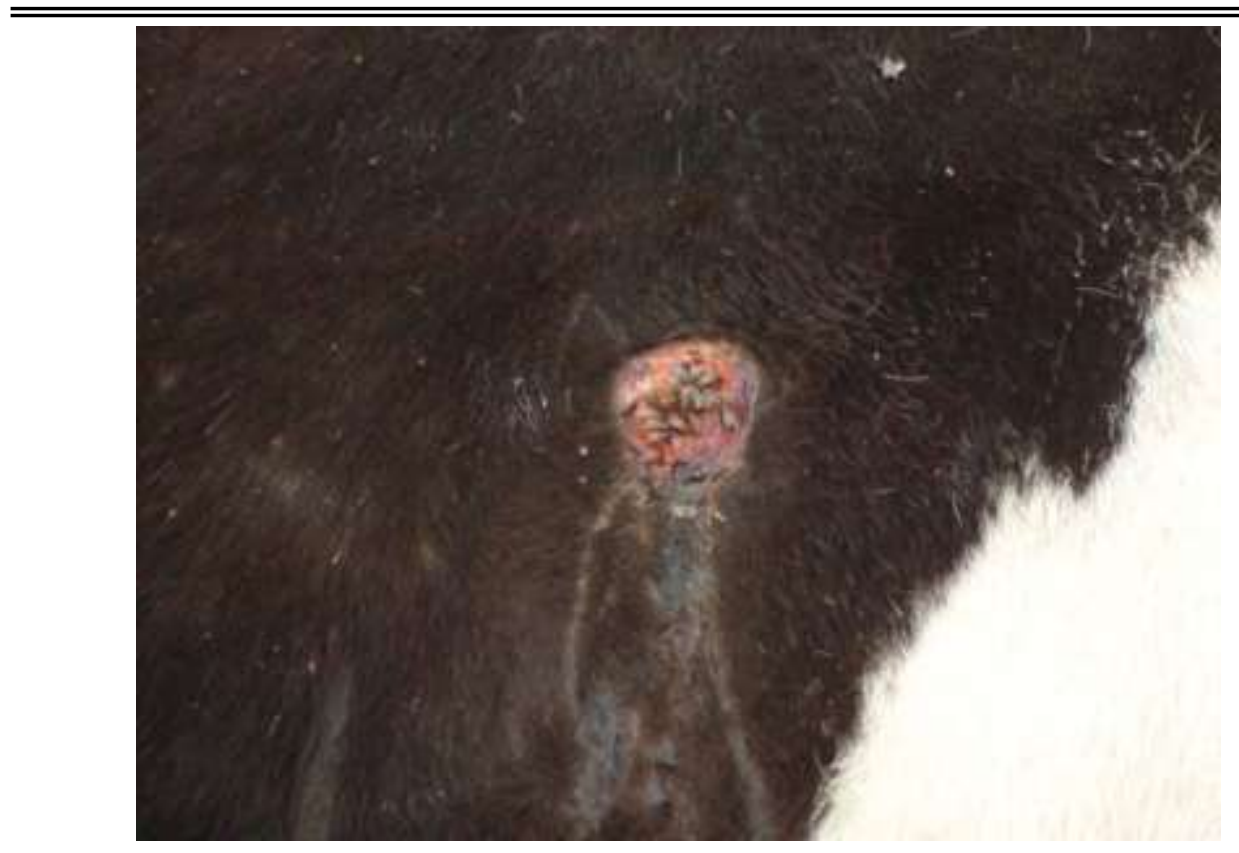

Fig. (7): Cattle showing ulcerative lesion on the chest.

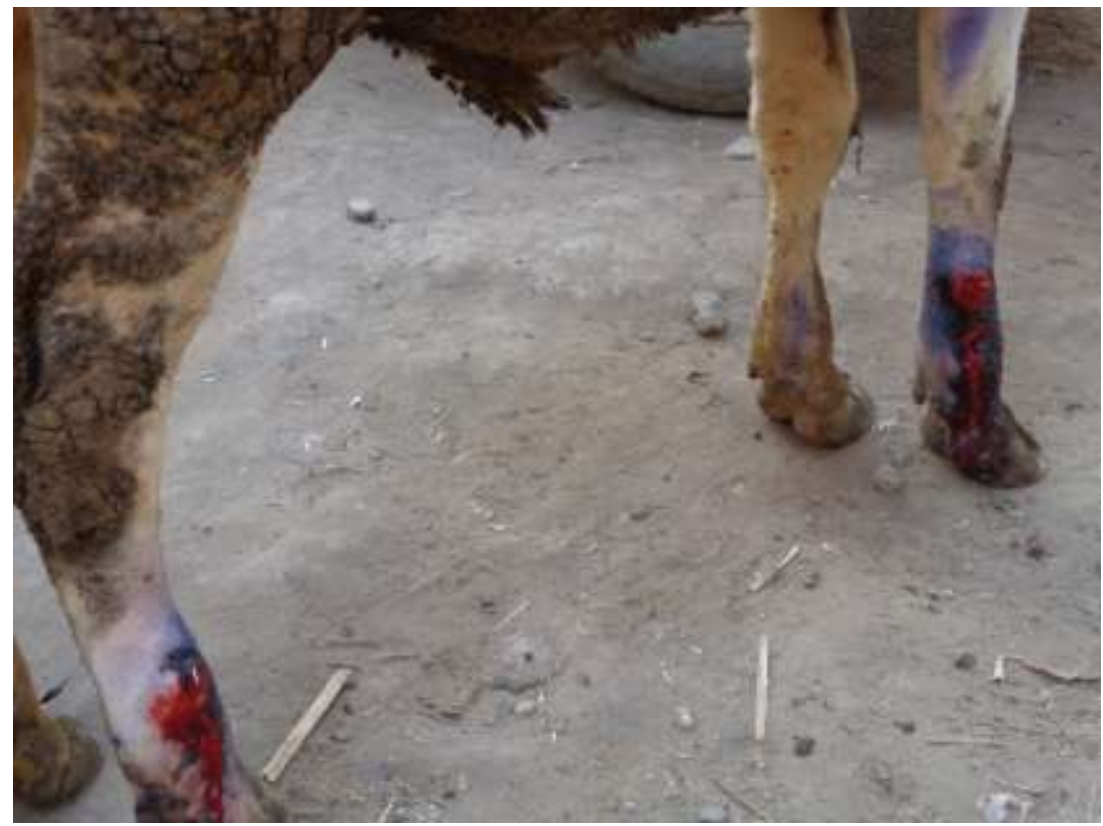

Fig. (8): Cattle showing ulceration at fore and hind right limbs. 


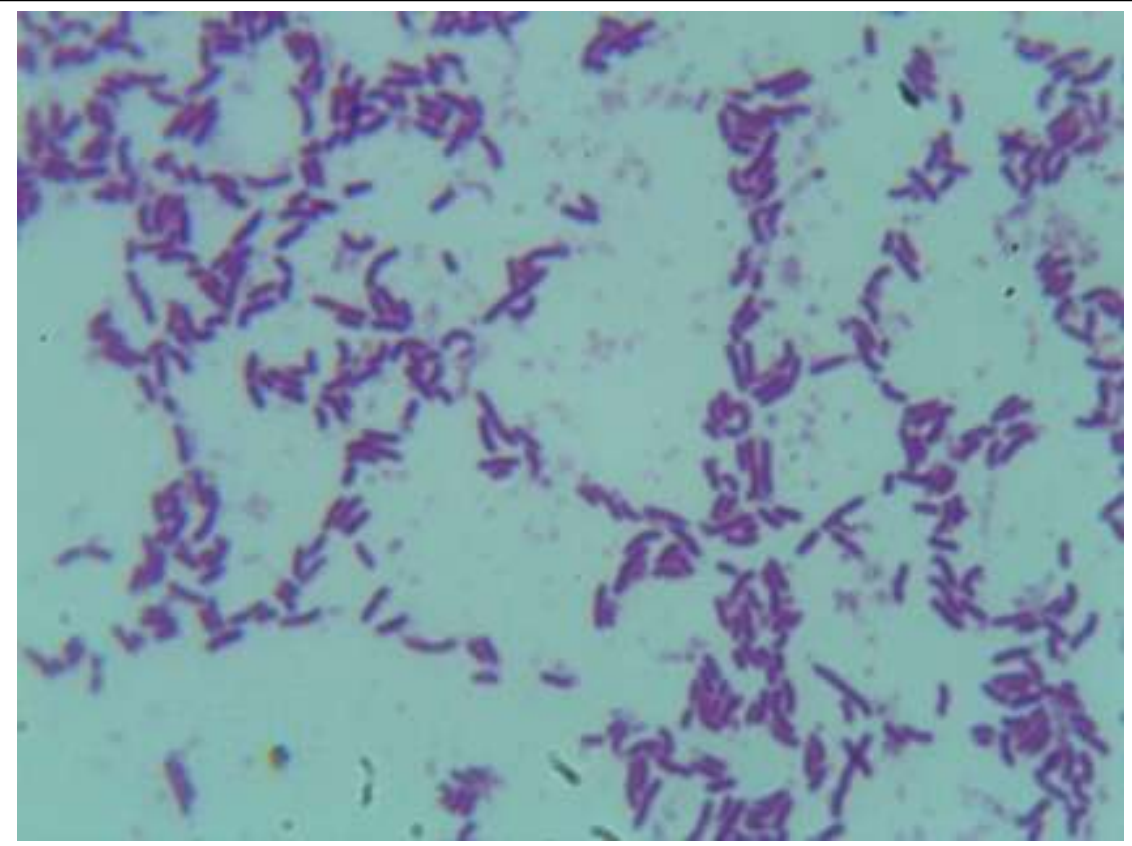

Fig. (9): Gram stained Corynebacterium pseudotuberculosis colonial smear.

Nodular form was reported in 4 buffalo and characterized by circumscribed or well defined localized swellings in the form of abscesses that were most commonly closed and located in the shoulder region and legs. Such swelling were inflammatory in nature with a variable sizes $(5-7 \mathrm{~cm})$. Regional lymph node of the lesion areas were found swollen.

The disease in two buffalo was terminated by complications that were hemoglobinuria and pneumonia. The complicated cases were associated with oedematous form. Hemoglobinuria was associated with subnormal temperature and respiratory distress shortly before death that may be a result of kidney failure or nephrosis. The pneumonia case was suffering from fever and respiratory disorders represented in hurried 
Oedematous Skin Disease, A Comparison Of ...

respiration, exaggerated vesicular lung sound and sometimes frothy discharges that come out from nostrils and finally temperature falls down to subnormal just before death.

Table (1): Clinical forms of OSD in cattle and buffalo during March to June, 2014 at Zefta-Gharbia, Egypt.

\begin{tabular}{|c|c|c|c|c|c|c|c|}
\hline \multirow{2}{*}{ Animals } & \multirow{2}{*}{ Examined } & \multicolumn{2}{|c|}{ Positive } & \multicolumn{4}{|c|}{ Clinical forms } \\
\hline & & No. & $\%$ & ulcerative & Edematous & Fistulous- edematous & Nodular \\
\hline Cattle & 112 & 7 & 6.3 & 7 & - & - & - \\
\hline Buffalo & 368 & 27 & 7.3 & 5 & 12 & 11 & 4 \\
\hline Total & 480 & 12 & 7.1 & 12 & 12 & 11 & 4 \\
\hline
\end{tabular}

\section{Results of bacteriological examination:}

The C. pseudotubeculosis has been identified in films prepared from lesions and stained by Gram stain as Chinese letter arranged Gram positive cocobacilli, figure 8 .

\section{Epidemiological findings and treatment trial results:}

All of animals treated early in the course of the disease with the protocol mentioned in materials and methods section were recovered. The course of ulcerative form was mostly several days without complications. The course of oedematous form extended to 2 weeks in $50 \%$ of animals which treated early in the course of the disease. While it was 6 weeks in the other $50 \%$ of animals which suffer from increases in swelling size due to progress of the condition and accumulation of pyogenic materials. 
The course of the outbreak was 4 months begin in March, 2014 and ended at the end of June, 2014 with its peak was at April and may, 2014. The temporal distribution of OSD outbreak is illustrated in table 2 and figure 9 .

All age groups were affected except that less than 9 months. Also, it was noticed that some of animals and places which got OSD in the previous outbreak suffered from the disease also in this outbreak.

Table (2): Temporal pattern of OSD outbreak at Zefta-Gharbia, Egypt( $\mathrm{N}=34)$.

\begin{tabular}{|c||c||c|}
\hline Month & Number of cases & $\%$ \\
\hline \hline March 2014 & 3 & 8.8 \\
\hline April 2014 & 12 & 35.2 \\
\hline May 2014 & 17 & 50 \\
\hline June 2014 & 2 & 5.9 \\
\hline
\end{tabular}

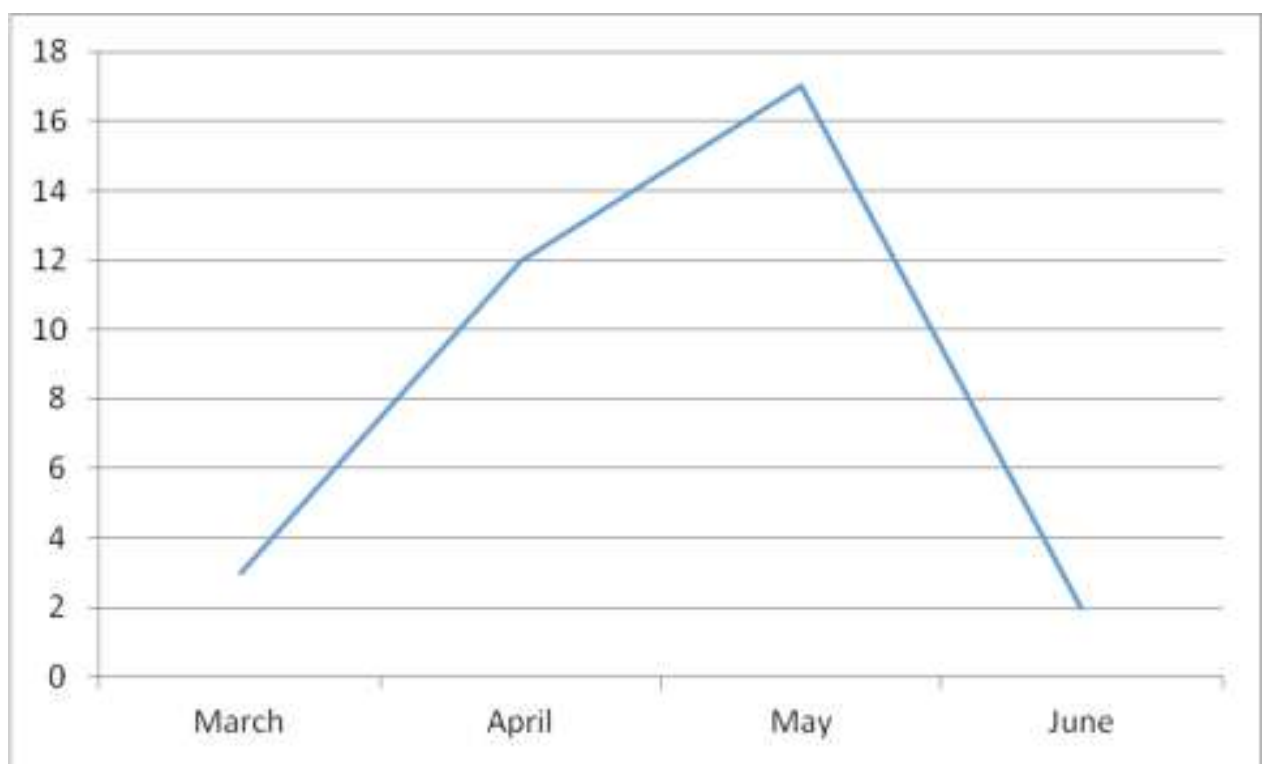

Fig. (9): Time-line plot for OSD outbreak at Zefta-Gharbia, Egypt. 


\section{DISCUSSION}

Oedematous skin disease is a specific disease that affects buffalo and cattle population in Egypt resulting in economic losses for the Egyptian farmers and consequently the National economy. Economic losses from OSD is mainly represented in treatment cost, reduction in milk and meat production or occasionally death (Selim, 2001: Syame, 2006 and Sayed et al., 2007).

OSD is endemic disease in Egypt with a temporal cyclic nature. In this study the epidemiological aspects and clinical signs of OSD among buffaloes and cows were studied in a new outbreak at Zefta region. In this outbreak, It was noticed that there were some new findings has emerged.

The total prevalence recorded in this outbreak was 7 while the prevalence among cows was estimated at 6.3. The prevalence among cows was much higher than those prevalences reported in the previous outbreaks. This may indicate increased adaptability of cattle to the disease.

Several clinical forms of OSD were found in this study: edematous, ulcerative, nodular and ulcerative forms, as previously reported in many previous studies (Al-Gaabary et al., 2005: Syame et al., 2008 and Oreiby, 2013). Systemic state of the diseased animals were not found changed indicating that it is a localized lesion and there is no systemic metastasis (Al-Gaabary and Ammar, 1999) except for complicated cases in which the diseased animal have fever. 
Edematous form of the disease was mostly detected in buffalo but never in cattle, whereas, ulcerative form was more common in cattle than in buffalo (Al-Gaabary et al., 2005).

Edematous form appeared as initial inflammatory swelling which later on turned to doughy, pyogenic and edematous swelling from which bloody or creamy pus was obtained by aspiration that is referred to pyogenic nature of C. pseudotuberculosis (Hamoda, 1996 and Zaghawa and El-Gharib, 1996).

Ulcerative form appeared as pyogenic cutaneous ulceration that had sudden onset and last for several days which indicates the role of dermonecrotic exotoxin that is produced from C. pseudotuberculosis (Quinn et al., 1994). Nodular form appeared as circumscribed abscesses which were inflammatory in nature and mostly located at chest or back of the affected animal.

Regional lymph nodes and/or lymphatics of the affected area were found affected in all diseased animals where lymphatic vessels were cord like while affected lymph nodes swellen to several times of its normal dimensions indicating that lymphatic tissues is a target for C. pseudotuberculosis as a facultative intracellular parasite (Conner et al., 2000).

Severity of clinical signs of OSD was known to be higher in buffalo than in cattle, but in this study which was performed in 2014 severity of the disease was nearly the same in both species indicating a change in virulence or adaptability of $C$. pseudotuberculosis toward cattle or even both. 
The Epidemiological findings in this study confirmed that OSD has temporal cyclic nature. The disease appeared after 2-3 years in the same places and even in the same animals. This finding needs further investigation to identify the reason of this phenomenon. This may be attributed to the immunity of the animal or the nature of the causative agent. Also, in this outbreak confirms the role of flies for spreading of infection and it's maintenance in different places especially with the disappearance of OSD in winter season. The course of the disease differed according to the nature of the lesion and the early treatment interference. Applying local antibiotic, quiet rest and apply fly repellent helped dramatically for shortening the course of Ulcerative lesions. While keeping blood oxytetracycline level high for 2-4 weeks accompanied with non steroidal anti-inflammatory was successful in oedematous lesions.

\section{REFERENCES}

- Abd El-Latif, M. M. (2011). Studies on some bacterial causes associated with Oedmetous Skin Disease in buffaloes in Dakahlia governorate. Assiut Vet. Med. J. 57(128):163-172.

- Abou-Zaid, A. A. (2001). Corynebacterium pseudotuberculosis in buffaloes, goats and sheep. Veterinary Medical Journal Giza. 49(3): 435-450.

- Addo, P. B. (1983). Role of the common house fly (Musca domestica) in the spread of ulcerative lymphangitis. Vet. Rec. 113:496-497. 
- Al-Gaabary, M. H. and Ammar, K. M. (1999). Clinical and epidemiological studies on buffalo lymphangitis in Gharbia governorate. 5thSci. Cong. Assiut, Egypt. 89-91.

- Al-Gaabary, M. H.; Ammar, K. M.; Osman, S. A. and Badr, A. M. I. (2005). Oedematous Skin Disease in buffaloes: clinical, epidemiological, histopathological and therapeutic studies. 8th Sci. Cong. Egyptian Society for Cattle Diseases. 65-80.

- Arab, R. M. H. ; Abou El-Hassan, D. G. ; Youssef, H. M. and AbdelHalim, M. M. (1988). A preliminary investigation on the double immunodiffusion technique in the diagnosis of Corynebacterium Pseudotuberculosis infection in sheep, buffaloes and cattle. Vet. Med. J. Giza. 36(2):189-197.

- Bailey, A. and Scott, S. (1990). Diagnostic microbiology 8th edition the C.V. Mosby Company. St. Louis.

- Barakat, A. A.; Osman, R. M.; Afifi, E. A.; Gad, A. S. And Shouman, M. T. (1985). Occurence of Oedematous Skin Disease in different provinces. J. Egypt. Vet. Med. Ass. 44: 225-231.

- Braverman, Y.; Chizor-Ginzburg, A.; Saran, A. and Winkler, M. (1999). The role of house flies (Musca domestica) in harbouring Corynebacterium Pseudotuberculosis in dairy herds. Israel Res. Sci. Tec. 18(13): 681-690.

- Conner, K. H.; Quirie, M. M.; Baird, G. and Donachie, W. (2000). Characterization of United Kingdom isolates of Corynebacterium pseudotuberculosis using pulsed field gel electroiphoresis. J. Clin. Microbiol., 38(7): 2633-2637. 
- Hamoda, F. K. (1996). Some studies on edematous skin disease. J. Egypt. Vet. Med. Assoc. 56(2): 213-221.

- Khater, A. R.; Bayoumi, A. N.; El-Deeb, S. and Salem, H. (1984). Studies on experimental infection of Corynebacterium ovis. II. Comparative studies on the effect of 2 strains in sheep. Assiut Vet. Med. J. 11(21): 95-99.

- Mostafa, M. E. M. (1984). Studies on the so-called Oedematous Skin Disease. M. V. Sc. Thesis. Fac. Vet. Med. Zagazig Univ.

- Oreiby, A. F. (2013). Studies on Corynebacterium infection in ruminants. $\mathrm{Ph}$. D. Thesis (Infectious Diseases), Kafrelsheikh University, Egypt.

- Quinn, S.G.; Carter, H. E.; Markey, B. K. and Carter, G. R. (1994). Clinical Veterinary Microbiology. 1st Ed. Mosby. Year Book Europe Limited.

- Rosenberger, G.; Dirksen, H. D.; Grunert, E.; Krause, D.; Stober, M. and Mack, R. (1979). Clinical examination of cattle 1st edition, Verlag Paul Parrey, Berlin and Hamburg.

- Sayed,S.;Rateb,H. Z.;Arafa, M.I.; Abdel-Hafeez,M.M.and Amer,A. A.(2007). Field study on buffaloes oedematous skin disease in Assiut governorate model study. Assiut Vet. Med. J. 53(114): 189-206.

- Selim, S. A. (2001). Oedematous skin disease of buffalo in Egypt. J. Vet. Med. B Infect. Dis. Vet. Public Health. 48: 241-258. 
- Syame,S.M.F.(2006). Preparation and evaluation of Corynebacterium Pseudotuberculosis vaccine in buffalo. Ph. D. Thesis, Faculty of Veterinary Medicine, Cairo University.

- Syame, S.; El-Hewairy, H. M. And Selim, S. A. (2008). Protection of buffaloes against oedematous skin disease by recombinant bacterin and toxoid bacterin vaccines. Global Veterinaria. 2(4):151-156.

- Zaghawa,A. A.and El-Garib, S. A. (1996). An outbreak of edematous skin disease in Alexandaria during 1994. Clinical investigation and assessment of epidemiological parameters. 7thSci. Cong. 17-19 Nov. 1996, Fac. Vet. Med. Assiut Egypt. 617-636.

- Zaki, E. R. (2004). Assessment of the role played by Corynebacterium Pseudotuberculosis exotoxin in inducing oedematous skin disease in buffaloes. J. Egypt. Vet. Med. Assoc. 64(6):171-181. 